\title{
Transpa rência e opacidade na gênese e desenvolvimento das línguas pidgins e crioulas: o caso das palavras interrogativas
}

\author{
Dante Lucchesi \\ Universidade Federal da Bahia (UFBA), Salvador, Bahia, Brasil \\ dante.lucchesi@gmail.com
}

DOI: $\underline{\text { http://dx.doi.org/10.21165/el.v45i1.1425 }}$

\begin{abstract}
Resumo
A partir da relação de implicação entre simplificação morfológica e incremento da transparência no funcionamento das línguas, este artigo focaliza como essas categorias atuam nos processos de pidginização e crioulização. A base empírica desta reflexão é fornecida por dados de mudanças que normalmente afetam as palavras interrogativas (e.g., onde, quando, quem) na gênese das línguas pidgins e crioulas. O objetivo deste artigo é contribuir para uma teoria mais equilibra da da mudança linguística, evitando os paradoxos que cercam as teorias tradicionais que se orientam por um princípio único, como o de que as línguas humanas tendem à simplificação em seu devir histórico.
\end{abstract}

Palavras-chave: transparência semântica; simplificação morfológica; línguas pidgins e crioulas; palavras interrogativas; mudança linguística.

Transparency and Opacity in the Genesis and Development of Pidgins and Creole Languages: the Case of Interrogative Words

\begin{abstract}
From the implication relationship between morphological simplification and increased transparency in the functioning of languages, this article focuses on how these categories operate in pidginization and creolization processes. The empirical basis of this reflection is provided by data englobing changes that usually affect interrogative words (e.g. where, when, who) in the genesis of pidgins and creole languages. The purpose of this article is to contribute to a more balanced theory of linguistic change, avoiding the paradoxes that surround traditional theories, which are guided by a single principle, like the conception that human languages tend to simplification in their historical development.
\end{abstract}

Keywords: semantic transparency; morphological simplification; pidgins and creole languages; interrogative words; linguistic change.

\section{Introdução}

A questão da transparência é tratada aqui no plano diacrônico, relacionada à questão da simplicidade estrutural, já que, em princípio, a simplificação morfoló gica estaria associada ao incremento da transparência semântica no funcionamento da língua. Assim, a primeira seção deste artigo focaliza a maneira como essas categorias são vistas na história das línguas humanas, para questionar a ideia, corrente na Linguística Histórica tradicional, de que as línguas tendem à simplificação e à transparência em seu devir histórico. Por outro lado, busca-se precisar as situações em que ocorreriam mudanças que implementam a simplificação morfológica e a transparência semântica. 
Tais mudanças estariam relacionadas às situações em que populações de falantes adultos têm de adquirir uma segunda língua em situações de aprendizado não sistemático, sendo a formação das línguas pidgins e crioulas as manifestações mais radicais de tais situações. Portanto, a segunda seção deste artigo focaliza a forma como a simplificação e a transparência atuam nos processos de pidginização e crioulização.

A terceira seção contém dados empíricos relativos às mudanças que normalme nte afetam as palavras interrogativas (e.g., onde, quando, quem $)^{1}$ na gênese das línguas pidgins e crioulas, para fundamentar a relação que existe entre esses processos e a simplificação morfológica e o incremento da transparência semântica.

Por fim, os elementos levantados ao longo desta reflexão são mobilizados em formulações que visam a contribuir com uma teoria mais geral sobre a mudança linguística.

\section{Transparência e simplificação na hi stória das línguas humanas}

No plano mais lato do devir histórico das línguas humanas, a questão da transparência está relacionada à questão da simplificação, pois tradicionalmente as teorias sobre a mudança linguística advogam uma tendência a uma simplificação morfológica que elevaria o grau de transparência nas línguas humanas, produzindo estruturas linguísticas em que a relação entre o significante e o significado é mais imediata. Um dos corolários dessa visão foi a formulação pelo linguista norte-americano Edward Sapir (1954[1921]) do conceito de deriva linguística, já no âmbito do Estruturalismo, no início do século XX. Segundo Sapir, a história das línguas seria orientada por uma tendência interna que definiria a direção das mudanças linguísticas através dos séculos. Essa tendência, por sua vez, seria determinada pela configuração estrutural da língua. Tomando como exemplo a história das línguas indo-europeias, esta é caracterizada por uma tendência constante à simplificação morfológica, como a perda da flexão nominal de caso, que se verifica na passagem do latim às línguas românicas.

Já a relação entre simplificação morfológica e transparência deriva do princípio de que transmitir uma informação por meios lexicais seria mais transparente do que transmitir essa informação por uma partícula gramatical, cuja percepção demanda maior esforço de decodificação. Enquanto as partículas gramaticais, que veiculam significados mais abstratos, exibem normalmente pouca substância fônica e são desprovidas de tonicidade, as palavras referências são normalmente vocábulos fonológicos, com acento próprio, sendo, portanto, mais facilmente percebidas e decodificadas, pois têm sua significação básica relacionada às coisas e aos processos do mundo real. Ou seja, uma língua que emprega o numeral dois seria mais transparente do que uma língua que emprega um morfema de dual, como o grego clássico, para expressar o mesmo conteúdo semântico. Assim, a simplificação morfológica da eliminação da flexão nominal de caso tornou as línguas românicas mais transparentes que o latim, na medida em que a indicação dos papéis temáticos de AGENTE e PACIENTE pela fixação da ordem SVO, que obedeceria a uma "sequência lógica" agente-ação-objeto, seria mais transparente que a veiculação dessa informação por meio de várias partículas gramaticais átonas finais, como ocorria com a alomorfia das desinências casuais no latim, o que possibilitava uma maior liberdade na ordem dos constituintes da frase. Assim, o lobo viu a menina seria

\footnotetext{
${ }^{1} \mathrm{Na}$ Teoria Gerativa, essas palavras são denominadas palavras-QU(WH-words).
} 
uma frase com mais transparência do que lupus puellam vidit, ou puellam lupus vidit, ou puellam vidit lupus etc. Da mesma forma, o sintagma de Maria em a casa de Maria é mais transparente que a forma flexionada Mariae em Mariae domus. Ou seja, as formas lexicais são mais transparentes que as formas gramaticais, e as construções analíticas são mais transparentes que as construções sintéticas flexionais. Portanto, a simplificação morfológica produz transparência, sobretudo no que concerne à eliminação da alomorfia, já que o máximo da transparência se daria na situação ideal caracterizada pela relação biunívoca em que cada significado é expresso por um e somente um significante.

Uma língua com um grau mais elevado de transparência seria, naturalmente, mais eficaz, em termos comunicativos, já que o processo de codificação e de decodificação dos enunciados linguísticos seria menos oneroso, envolvendo um número menor de operações de processamento. E, se os falantes, de uma maneira mais ou menos consciente, buscam sempre a eficácia comunicativa em suas interações verbais, é previsível que as línguas tenderiam, em seu devir histórico, à simplificação morfológica. Na linguística histórica do século XIX e início do século XX, esse princípio do menor esforço teve grande aceitação (MARTINET, 1955).

A grande falácia de tal raciocínio é achar que o real se conforma aos ideais da razão. Com efeito, a ordem SVO é a mais frequente nas línguas humanas, mas nada mais impróprio, no que concerne à dinâmica da linguagem, do que afirmar que a ordem SVO é mais lógica. Levando esse raciocínio às últimas consequências, numa operação que a Lógica denomina reductio ad absurdum, seríamos levados a pensar, por exemplo, que os japoneses, que falam uma língua SOV, seriam menos lógicos que os italianos, que falam uma língua $\mathrm{SVO}$, o que é muito pouco plausível, fora dos esquemas mentais do colonialismo europeu que predominaram até o início do século XX. É mais provável que a maior frequência de uma estrutura gramatical nas línguas humanas se deva a um acaso histórico do que a uma tendência universal da linguagem (LASS, 1980). Porém, em função de suas fragilidades epistemológicas, a Linguística toma como mais naturais, mais funcionais, mais ótimas as formas linguísticas mais frequentes nas línguas humanas, ignorando a problemática de classificar formas linguísticas que funcionam perfeitamente em muitas línguas como menos naturais, pouco funcionais e não ótimas.

Mais do que um problema da Linguística, essa é uma contradição que perpassa todo o fazer da ciência moderna, ao procurar enquadrar o real nos esquemas de uma razão subjetiva, produzindo uma grande inadequação entre suas predições e os fatos.

$\mathrm{O}$ funcionamento das línguas, por exemplo, é identificado à uniformidade e à homogeneidade, desde o modelo inaugural da Linguística Moderna, o Estruturalismo, até a corrente contemporânea do Gerativismo Minimalista (LUCCHESI, 2011), mas a heterogeneidade é condição imprescindível ao funcionamento de toda língua viva (WEINREICH; LABOV; HERZOG, 2006[1968]). No famoso Curso de Linguística Geral, Saussure (1973[1916]) teria afirmado que a língua rejeita a variação linguística e, desde então, a mudança linguística é vista como um processo de deterioração da língua (WEINREICH; LABOV; HERZOG, 2006). Um seguidor ortodoxo de Saussure chegou a afirmar que, a rigor, a língua não deveria mudar (Bertil Malmberg apud COSERIU, 1979, p. 15-16), quando as línguas vivem em ininterrup to processo de mudança, sem que isso afete o seu funcionamento. O problema de pensar o funcionamento da língua em meio a mudanças e a heterogeneidade é que esse pensamento é claramente contra intuitivo. Porém, conquanto busque se apartar do senso-comum, muitos dos estereótipos 
ingênuos ou ideologicamente motivados do cotidiano se insinuam sorrateiramente no pensamento científico, gerando axiomas falaciosos que não têm uma base empírica consistente.

Afirmar, por exemplo, que a história das línguas indo-europeias se caracteriza por uma tendência constante à simplificação é uma falácia da generalização apressada, também denominada falácia do acidente convertido, pois um rápido exame pode identificar mudanças, na passagem do latim às línguas românicas que caminham em direção contrária. Tal é o caso, por exemplo, da formação do artigo definido, criando, nas línguas românicas, uma partícula gramatical de significado sutil e abstrato, que não existia no latim; o que positivamente não pode ser visto como um processo de simplificação morfológica que incrementa a transparência. $O$ mesmo se pode afirmar da flexão de gênero, que a rigor não existia em latim e tem uma funcionalidade crescente nas línguas românicas, embora, no mais das vezes, não tenha qualquer valor semântico, tanto que sua arbitrariedade se evidencia na diferença de gênero de palavras como leite, masculino em português, mas feminino em espanhol (la leche); flor, feminino em português, mas masculino em italiano (ilfiore); e mar, masculino em português, mas feminino em francês (la mer). Não se pode ver aí, positivamente, um incremento da transparência.

Na melhor das hipóteses, a alegada tendência à simplificação morfológica seria um epifenômeno, para usar uma expressão cara aos gerativistas. Uma sequência de mudanças que levam à simplificação morfológica e à transparência semântica não significa necessariamente que exista uma tendência evolutiva determinada pela estrutura interna da língua nessa direção. Trata-se de um raciocínio falacioso do tipo non sequitur, motivado pela hipostasia do sistema linguístico que enformou a visão estruturalista de língua (LUCCHESI, 2004). Assim, o gerativista David Lightfoot considerou metafísica a ideia de uma deriva linguística secular, pois ela não se sustenta em face de uma teoria consistente da mudança linguística, como se pode ver na seguinte formulação, que vê a transmissão da língua de uma geração a outra como o momento crucial da mudança gramatical:

Línguas são adquiridas e gramáticas são construídas por indivíduos de cada geração. Eles não têm memórias raciais de forma a saber, em qualquer sentido, que suas línguas estão gradualmente se desenvolvendo de, digamos, um tipo SOV para um tipo SVO, e que ela deve continuar seguindo nessa direção. ${ }^{2}$ (LIGHTFOOT, 1979, p. 391)

A alegada tendência geral das línguas humanas à simplificação enseja outro s problemas lógicos, tais como: por que motivo as línguas humanas surgiriam mais complexas para depois irem se simplificando ao longo dos séculos? Além disso, essa alegada tendência entra em contradição com o estado atual das línguas humanas, em que se observa certo equilibrio entre simplicidade e complexidade, bem como entre transparência e simplicidade, como bem observou William Labov (1982, p. 59):

\footnotetext{
${ }^{2}$ Languages are learned and grammars constructed by the individuals of each generation. They do not have racial memories such that they know in some sense that their language has g radually been developing from, say, an SOV and towards a SVO type, and that it must continue along that path.
} 
Princípios unidirecionais produzem logicamente uma teoria desequilibrada da mudança. Qualquer princípio de simplificação requer um princípio de complicação, e uma teoria de transparência crescente deve ser acompanhada de uma explicação sobre como a opacidade foi criada. Parece evidente que a maioria das línguas mantém um razoável equilibrio a esse respeito. ${ }^{3}$

E, como explicar a formação de línguas com uma estrutura gramatical mais complexa? Além do que, como bem observou o crioulista Jeff Siegel (2008), não é uma tarefa fácil comparar a complexidade da gramática como um todo entre as línguas humanas, pois normalmente uma língua que é mais complexa que outra em uma porção da gramática, ao passo que é mais simples em outra porção. Por exemplo, as línguas europeias, no geral, exibem uma morfologia verbal mais complexa que muitas línguas indígenas brasileiras, ou línguas bantas, ou ainda línguas da Melanésia, no Pacífico. Mas, todas essas últimas exibem uma morfologia nominal muito mais complexa do que a maioria das línguas europeias.

O que se coloca em questão, então, é a própria extensão dos conceitos de simplicidade e transparência, sobretudo no sentido de sua identificação com os conceitos de natural e ótimo, o que produz relações de implicação do tipo:

mais simples $\rightarrow$ mais natural $\rightarrow$ mais transparente $\rightarrow$ mais ótimo $\rightarrow$ mais fácil

Se, por meio de um raciocínio especulativo, colocássemos um falante nativo do latim em face das atuais línguas românicas, poderíamos supor que, para esse falante latino, essas línguas seriam muito mais opacas do que o latim, que etiquetava os constituintes da frase, enquanto os falantes das línguas românicas identificam essas funções sem qualquer marca explícita, mesmo nas frases que fogem à ordem canônica SVO, em função de uma diferença sutil na entoação, como em: A menina, o lobo viu. Da mesma forma, não é muito fácil convencer um nigeriano, falante nativo do iorubá, que o tom é um mecanismo fonológico menos natural do que o acento de intensidade. Ele poderia, com razão, considerar tal raciocínio um produto de uma ideologia eurocêntrica.

Há um conjunto robusto de evidências empíricas que contrariam a ideia de que as línguas possam ser, em seu conjunto, mais simples ou mais complexas do que outras, ou que sejam in totum mais transparentes ou mais opacas. Se assim o fosse, seria o caso de haver línguas que demandariam mais tempo para serem adquiridas como línguas maternas do que outras. Contudo, todos os resultados das pesquisas empíricas sobre a aquisição de língua materna apontam na direção contrária: as crianças de todas as línguas naturais desenvolvem sua competência linguística mais ou menos no mesmo período de tempo, seguindo as mesmas etapas. Uma implicação muito perigosa daquela premissa seria, então, pensar que as crianças de uma língua mais complexa desenvolveriam sua capacidade linguística mais rapidamente, porque seriam racialmente mais capazes.

A sistematização gerativista da ideia de uma faculdade inata da linguagem comum a todos os indivíduos da espécie humana (CHOMSKY, 1986) descortinou um campo

\footnotetext{
3 Unidirectional principles logically produce an unbalanced theory of change. Any principle of simplification requires a principle of complication, and a theory of increasing transparency must be accompanied by an account of how opacity is created. It seems evident that most languages maintain a reasonable balance in this respect.
} 
muito profícuo de reflexão sobre as línguas humanas, que interdita qualquer raciocínio de matiz racista, embora os êxitos desse modelo na explicação do funcionamento real das línguas sejam muito modestos, em função dos vícios de um formalismo racionalista, que só se sustentam em face de procedimentos de verificação empírica muito frágeis e sobejamente questionados (LABOV, 2008[1972], inter alia).

A ideia de uma Gramática Universal, ou seja, uma Faculdade Humana da Linguagem, implica que todos os dispositivos gramaticais das línguas naturais estão em latência na mente de cada um dos indivíduos da espécie ao nascer e são ativados ou não em função da natureza dos dados linguísticos primários (DLP) disponíveis no período crítico de desenvolvimento da língua materna; ou seja, de tudo quanto a criança ouve em seus primeiros anos de vida (CHOMSKY, 1986). Assim, uma criança indígena brasileira que não seja privada do direito natural de adquirir a língua nativa de seu povo não fará mais esforço para adquirir a categoria gramatical da evidencialidade (presente em muitas línguas indígenas brasileiras e que codifica gramaticalmente a natureza da fonte da informação veiculada pela frase $)^{4}$ do que a outra criança brasileira que adquire como língua materna o português, que não marca essa categoria gramatical. Se a criança encontra nos DLP evidências robustas do mecanismo de marcação da evidencialidade, ela ativa essa categoria gramatical em sua competência linguística; caso contrário, ela bloqueia essa categoria gramatical; o esforço, porém, é o mesmo em ambos os casos. Da mesma forma que uma criança de uma das línguas da Melanésia, que têm até cinco valores para a categoria nominal de número, não precisará despender mais esforço que uma criança de uma língua europeia que só tem dois valores para essa categoria (o singular e o plural), porque todos os potenciais valores de todas categorias gramatica is estão virtualmente presentes na mente da criança, que ativará tantos quantos forem os valores presentes em seu DLP.

O problema só se coloca quando um indivíduo adulto precisa adquirir uma segunda língua após a adolescência, quando os dispositivos de aquisição da língua materna não estão mais acessíveis em sua mente. Nessa condição, ele terá muita dificuldade para assimilar ou mesmo perceber os dispositivos gramaticais da língua que pretende adquirir (VAINIKKA; YOUNG-SCHOLTEN, 2006), nomeadamente os que não estão presentes na gramática de sua língua nativa e cujas estruturas mentais foram desativadas, portanto, no processo de aquisição de sua língua materna. Por essa razão, esses dispositivos gramaticais lhe pareceram ilógicos, truncados, exóticos ou mesmo antinaturais.

Esses julgamentos do senso-comum, eivados muitas vezes de influxos ideológ icos de natureza etnocêntrica, têm fornecido o substrato de teorias linguísticas sobre simplicidade, naturalidade e otimalidade nas línguas humanas. A rigor, tudo o que não é da nossa língua é difícil, ilógico ou antinatural, o que confere uma grande dose de subjetividade a tais conceitos. A percepção, por exemplo, de que a diferença fônica entre avô e avó é objetiva e, portanto, acessível a qualquer pessoa com uma audição normal não encontra respaldo entre os falantes nativos do espanhol, que não têm essa oposição fonológica em sua competência linguística e têm muita dificuldade em dominar essa oposição fonológica quando aprendem o português. E a estranheza que os brasileiros experimentam ao saber disso é a mesma que os franceses têm, ao saber que os brasileiros

\footnotetext{
${ }^{4}$ Basicamente, esse dispositivo dispõe de um morfema que indica se o evento descrito na frase foi presenciado pelo falante e de outro morfema que indica que o falante ouviu a informação de outrem.
} 
não conseguem ouvir a diferença fônica clara e evidente, que existe para eles, entre as formas do singular e do plural do artigo definido masculino, como, por exemplo, nos sintagmas le livre e les livres.

Os questionamentos aqui formulados não implicam que as categorias da simplicidade e da transparência não tenham qualquer valor heurístico para o entendimento do devir da linguagem humana em geral. $O$ que se questiona aqui são as simplificações e generalizações que carecem de maior fundamentação empírica e consistência teórica. Não parece plausível que exista uma tendência universal à simplicidade e à transparência na história da língua. Isso não significa que não existam situações que desencadeiam mudanças que eliminam substância morfológica, incrementando, em princípio, a simplicidade e a transparência nas línguas. A partir dessa premissa, a primeira questão que se coloca é identificar que situações específicas são essas. E, se esta hipótese se confirmar, talvez o que exista de latente no devir das línguas humanas, em situações normais de transmissão geracional, seja exatamente o contrário do que se tem tradicionalmente pensado.

\section{Transparência e simplificação na formação das línguas pidgins e crioulas}

Ao que tudo indica, a distinção entre os planos da aquisição de língua materna e da aquisição de segunda língua se coloca como crucial para o entendimento de como as dicotomias entre simplicidade e complexidade e transparência e opacidade atuam na estruturação das línguas humanas e, sobretudo, na mudança linguística, pois, se tais dicotomias parecem não ter qualquer interferência na aquisição da língua materna, tudo indica que são determinantes no processo de aquisição de segunda língua.

Nessa perspectiva, a gênese e o desenvolvimento das línguas pidgins e crioulas seriam o campo de pesquisa ideal para compreender o papel de tais dicotomias, pois essas línguas têm sua origem na aquisição de uma segunda língua por uma grande população de falantes adultos (em muitos casos, falantes de várias línguas mutuamente ininteligíveis), em condições muito adversas, como as situações de escravidão, produzidas no bojo da colonização europeia da África, América, Ásia e Oceania, entre os séculos XVI e XIX.

Tomemos, por exemplo, a situação de africanos escravizados em uma grande plantação, no Caribe, no século XVIII, que eram obrigados a usar a língua dos seus senhores para se comunicar e sobreviver em condições de violenta sujeição. A aquisição dessa segunda era, porém, muito precária, não apenas por que o acesso desses aprendizes aos modelos da língua alvo era muito limitado, mas também porque eles não tinham, em geral, interesse em desenvolver uma proficiência nessa língua semelhante à dos seus senhores (RAMPTON, 1997). Assim, formava-se um código emergencial de comunicação interétnica que continha um reduzido número de palavras da língua dominante, sendo praticamente desprovido de estrutura gramatical. Em Crioulística, esse código tem sido denominado jargão ou pré-pidgin (SIEGEL, 2008).

Quando esse pré-pidgin passava a ser usado também na comunicação entre os falantes do grupo dominado, porque, em muitos casos, estes falavam línguas diferentes e mutuamente ininteligíveis, ocorria, forçosamente, uma ampliação do espectro funcional do pré-pidgin, criando as condições para a sua regramaticalização. Esse processo dava ensejo a uma língua pidgin expandida ou estabilizada (MÜHLḦ̈USLER, 1986). Mesmo 
não sendo a língua materna da maioria de seus utentes, um pidgin pode se tornar uma língua com uma estrutura gramatical comum às demais línguas humanas, sendo empregado nas mais variadas funções, inclusive na escrita e nos meios de comunicação de massa, como ocorre com o tok pisin, em Papua-Nova Guiné, na Oceania.

Como o pidgin se expandia gramaticalmente num contexto de pouco acesso aos dispositivos gramaticais da língua dominante, os seus falantes recorriam ao repertório gramatical de sua(s) língua(s) nativa(s) para desenvolver sua gramática, em um processo denominado transferência do substrato (SIEGEL, 2008). Deve-se observar, entretanto, que muitos dos mecanismos gramaticais presentes na língua dominante na situação de contato, da qual se origina a grande maioria das palavras do pidgin (por essa razão, também chamada língua lexificadora), se perdem no processo inicial de aquisição e não são reconstituídos no processo de gramaticalização do pidgin. Tal é o caso dos mecanismos gramaticais que não têm valor informacional, como, por exemplo, as regras de concordância nominal e verbal e as regras de movimento, que tornam as línguas mais opacas. Além dessa simplificação morfológica, as línguas pidgins se caracterizam por uma otimização dos recursos gramaticais de que dispõem, sendo a alomorfia rara ou inexistente nessas línguas. Assim, as línguas pidgins se destacam por seu elevado grau de simplicidade e transparência.

A maioria dos pidgins que se formou na África e no Caribe, no bojo do Colonialismo europeu, entre os séculos XVI e XVIII, tornou-se a língua materna dos filhos de seus falantes, ocorrendo, assim, a crioulização. As línguas crioulas, conquanto sejam línguas plenas, já que são línguas maternas de seus falantes, transmitidas com o recurso à faculdade inata da linguagem, também se caracterizam por um aparato gramatical reduzido, contendo, pelo menos no momento inicial de sua formação, os mecanis mos essenciais para o funcionamento pleno de uma língua humana ${ }^{5}$. Essa seria a situação arquetípica. Obviamente, houve muita variação entre os processos de crioulização, de modo que os resultados estruturais das gramáticas das línguas crioulas serão diferenciados, em função dos valores de variáveis sociais que plasmaram a situação em que essas línguas se formaram, como, por exemplo, a proporção numérica entre os falantes do grupo dominante e dos grupos dominados, uma maior ou menor homogeneidade linguística dos grupos dominados, e assim por diante. Esses fatores vão determinar um maior ou menor acesso aos modelos da língua dominante, por um lado, e um grau mais ou menos elevado de transferência de estruturas gramaticais da(s) língua(s) do substrato. Um maior acesso à língua dominante, bem como uma influência maior do substrato, possibilitaria a transmissão de mecanismos gramaticais que, numa situação distinta, não figuram na gramática do crioulo.

De qualquer forma, os processos de otimização e maximização dos recursos gramaticais caracterizam a essência da pidginização e da crioulização. Nesse sentido, o crioulista John McWorter (2001) definiu as línguas crioulas como as línguas com as gramáticas mais simples do mundo. Essa simplificação se traduz na eliminação da maioria dos mecanismos gramaticais sem valor informacional, como as regras de concordância e de movimento. Como a simplificação morfossintática, que caracteriza a formação das línguas pidgins e crioulas, implica igualmente, incremento da transparência, crioulistas, como Seuren e Wekker (1986), buscam explicar a especificidade dessas línguas com base no princípio de transparência semântica, segundo

\footnotetext{
${ }^{5}$ Aqui é retrata
} 
o qual, nas línguas pidgins e crioulas, os conteúdos semânticos são extraídos diretamente da estrutura superficial, sem relações intermediárias complexas, como muitas vezes ocorre nas línguas humanas.

Portanto, as pesquisas sobre as línguas pidgins e crioulas têm reunido evidências de que as situações de contato massivo entre línguas que envolvem a aquisição de uma segunda língua por uma população de adultos, em situações adversas de dominação e sujeição, desencadeiam mudanças que produzem simplificação morfológica (TRUDGILL, 2009). Em um espectro mais amplo, pode-se dizer que as situações de contato massivo entre línguas produzem simplificação morfológica, e a fortiori incremento da transparência, mesmo quando a variedade que se forma não é uma língua pidgin ou crioula típica, mas uma variedade da língua dominante na situação de contato (LUCCHESI, 2008; LUCCHESI; BAXTER, 2009).

A próxima seção retratará a mudança que costuma afetar um dispositivo gramatical geral das línguas humanas, as palavras interrogativas, em situações de contato massivo entre línguas, particularmente nas situações de pidginização e crioulização. Como se poderá ver, essa mudança eleva o grau de transparência da língua, na medida em que substitui uma partícula gramatical sintética por uma construção analítica que combina uma partícula gramatical com uma palavra referencial.

\section{As palavras interrogativas nas línguas pidgins e crioulas}

Um exemplo notável de incremento da transparência na crioulização seria a mudança que costuma afetar a forma das palavras interrogativas. As palavras interrogativas são dispositivos gramaticais universais que têm um amplo espectro funcional, servindo não apenas para formar perguntas com variável, mas também para encetar orações completivas e funcionando também como relativizadores, como exemplificado, respectivamente, em (1), (2) e (3):

(1) Quem comeu o bolo?

(2) Não sei quem fez isso?

(3) Não encontrei o funcionário a quem entreguei o documento.

Em Roots of language, seu estudo clássico sobre a crioulização, Derek Bickerton (1981) propôs que uma das características da crioulização seria a formação do que passou a ser chamado palavras interrogativas bimorfêmicas. Nesse processo, a palavra interrogativa da língua lexificadora é substituída por uma combinação entre um complementizador neutro e um nome que expressa o conteúdo semântico da palavra interrogativa, como se pode ver a seguir:

$\begin{array}{ll}\text { Onde } & \text { que-lugar } \\ \text { Quem } & \text { que-pessoa } \\ \text { Quando } & \text { que-tempo } \\ \text { Por que } & \text { que-causa } \\ \text { Como } & \text { que-modo }\end{array}$

A seguir, exemplos da forma que a interrogativa assume em alguns crioulos:

(4) wisaid yu Bin de?

(Guianense)

que-lado você vir de

Where do you come from?

De onde você vem? 
Onde você viu o peixe?

Ke situ e pe mi n-e-e?

(Santomense)

que-lugar ele pôr milho nele

Onde ele pôs o milho?

Para Muysken e Veenstra (1994, p. 124), a formação de palavras interrogativas bimorfêmicas se ajustaria perfeitamente aos parâmetros que determinam a emergência das línguas pidgins e crioulas, particularmente no que diz respeito ao princípio da transparência semântica, proposto por Seuren e Wekker (1986). Os autores colocam as palavras interrogativas bimorfềmicas ao lado do sistema de tempo, modo e aspecto baseado em partículas pré-verbais, que substitui as formas flexionadas das línguas de superestrato europeias nas línguas crioulas, como evidência de tal princípio. Formas verbais perifrásticas, como já fala, ou palavras interrogativas bimorfêmicas, como que tempo, teriam um significado muito mais transparente do que as formas sintéticas falei $\mathrm{e}$ quando, da língua lexificadora, e suas formas embrionárias devem surgir já no momento inicial do contato, quando a população de falantes adultos lança mão da língua do grupo dominante para a comunicação interétnica, dando origem aojargão ou pré-pidgin. E isso se encaixa perfeitamente no que a teoria prevê para a aquisição de segunda língua por adultos em situações não sistemáticas, como exposto na seção anterior deste artigo.

Contudo, ao longo do processo de expansão funcional e gramatical do pidgin e/ou de crioulização, essas formas analíticas sofreriam a concorrência das formas sintéticas da língua lexificadora, de modo que, ao lado da palavra bimorfêmica, pode-se firmar uma forma sintética, como ken 'quem', no papiamento, ou mesmo uma forma híbrida, como wen time 'quando' (lit. 'quando tempo'), no jamaicano. Assim, um sistema mais transparente de palavras interrogativas bimorfêmicas pode-se tornar progressivamente opaco, com o passar do tempo (MUYSKEN; VEENSTRA, 1994, p. 125). O resultado mais geral disso seria um quadro de variação na forma das palavras interrogativas, como se observa em muitas línguas crioulas particularmente no contexto do continuum postcrioulo (RICKFORD, 1987).

Um caso interessante de sistema misto com variação pode ser encontrado no papiá Kristang, crioulo português de Malaca, no sudeste asiático, como se pode ver no quadro abaixo que montamos com base na descrição de Alan Baxter (1988, p. 77 e 189-190):

Quadro 1. Forma das palavras interrogativas em papiá kristang.

\begin{tabular}{|l|l|l|}
\hline Português & \multicolumn{1}{|c|}{ Papiá Kristang } & \multicolumn{1}{c|}{ Interpretação } \\
\hline onde & $\begin{array}{l}\text { úndi } \sim \text { kí banda ('que banda', no } \\
\text { sentido de 'que lado') }\end{array}$ & forma sintética variando com forma bimorfêmica \\
\hline quando & kóra $\sim$ kí ora $\sim$ kí tempu & $\begin{array}{l}\text { forma bimorfêmica aglutinada variando com } \\
\text { formas claramente analíticas }\end{array}$ \\
\hline por que & kifói $\sim$ kí kausu & $\begin{array}{l}\text { forma aglutinada variando com forma analítica } \\
\text { distinta }\end{array}$ \\
\hline como & kái $\sim$ klai & $\begin{array}{l}\text { variação na forma aglutinada derivada de antiga } \\
\text { forma analítica kí laia }\end{array}$ \\
\hline
\end{tabular}

Considerando a diferenciação nos processos de crioulização, em função dos valores das variáveis sociais que o estruturam (como discutido na seção anterior), a 
formação de palavras interrogativas bimorfêmicas estaria relacionada aos contextos mais radicais de crioulização, enquanto que as formas sintéticas estariam relacionadas a uma maior influência da língua lexificadora. Por outro lado, a evolução fonética da forma da palavra interrogativa bimorfêmica pode obscurecer a sua composição, tornando a forma mais opaca.

Portanto, os processos de pidginização e crioulização se revelam como momentos em que ocorrem mudanças linguísticas que incrementam a simplicidade morfológica e a transparência semântica nas línguas, como aqui demonstrado em relação às palavras interrogativas. Porém, uma vez constituídas, essas línguas podem sofrer mudanças que costumam afetar o devir histórico de todas as línguas humanas e que tendem a tornar as estruturas mais gramaticalizadas, em função do processo normal de gramaticalização, fartamente documentado na história das línguas humanas, e consequentemente mais opacas. Tais mudanças que ocorrem na transmissão normal da língua de uma geração a outra acabam por diminuir o grau das línguas, na medida em que incrementam seus dispositivos morfológicos.

\section{Conclusão}

A análise das mudanças que normalmente afetam as palavras interrogativas na formação das línguas pidgins e crioulas aqui apresentada trouxe elementos interessantes para a compreensão de como a dicotomia transparência e opacidade se manifesta no devir histórico das línguas humanas. Considerando a relação de implicação entre simplicidade morfológica e transparência semântica, podemos concluir que, ao contrário de serem processos inerentes ao devir histórico normal das línguas, a simplificação e o increme nto da transparência ocorrem em situações específicas, como as de contato linguístico massivo. Indo além, é possível mesmo postular que a situação regular de transmissão geracional de uma língua seria, ao contrário, a da gramaticalização e do incremento da opacidade. Nessa perspectiva, a teoria da mudança linguística fica mais balanceada, diferentemente do que ocorria com a visão tradicional de que as línguas normalmente tenderiam à simplificação e à transparência. Assim, uma compreensão mais adequada da evolução linguística seria alcançada, conjugando essas tendências contrárias: de um lado, a tendência à gramaticalização, que implica complexificação morfológica e aumento da opacidade e que seria inerente à transmissão geracional regular das línguas; de outro lado, estariam as situações de contato massivo entre línguas (cuja manifestação mais radical seria a dos processos de pidginização e crioulização) que desencadeariam mudanças de simplificação morfológica e a fortiori de incremento da transparência.

Embora as situações de contato entre línguas seja uma constante na história da humanidade, pode-se argumentar que línguas de comunidades muito isoladas tenderiam a ser excessivamente complexas e opacas. Conquanto isso possa ser, pelo menos em parte, verdadeiro, seria preciso pensar em mudanças simplificadoras que ocorressem independentemente das situações de contato. Uma solução poderia ser encontrada no plano da fonologia, já que haveria uma tendência latente ao enfraquecimento de partículas átonas finais. E a grande maioria das partículas gramaticais são sufixos átonos. A ideia de que marcas gramaticais tendem a desaparecer em função de sua erosão fonética não é nova na Linguística, sendo consagrada desde, pelo menos, a formulação de Talmy Givón (1979) sobre o processo de gramaticalização. Esse enfraquecimento fonético das marcas gramaticais favoreceria o emprego de formas analíticas, ou mesmo de itens lexicais, para 
expressar o conteúdo semântico da partícula gramatical, aumentando o grau de transparência semântica das línguas.

Neste artigo, buscamos contribuir para a formulação de uma teoria mais equilibrada da mudança linguística, no sentido de Labov (1982), já que as teorias que se baseiam em um único princípio geral, quer seja em direção à simplicidade e à transparência, quer seja em direção à complexidade e à opacidade, não dão conta do relativo equilibrio que existe entre as línguas em relação a essas duas dicotomias.

\section{REFERÊNCIAS}

BAXTER, A. A Grammar of Kristang (Malacca Creole Portuguese). Canberra: Pacific Linguistics, 1988. $241 \mathrm{p}$.

BICKERTON, D. Roots of language. Ann Arbor: Karoma, 1981. 351 p.

CHOMSKY, N. Knowledge of language: its origin, nature and use. New York: Praeger, 1986. 307 p.

COSERIU, E. Sincronia, diacronia e história: o problema da mudança lingüística. Rio de Janeiro: Presença, 1979. 245 p.

GIVÓN, T. On understanding grammar. New York: Academic Press, 1979. 378 p.

LABOV, W. Building on empirical foundations. In: LEHMANN, W. P.; MALKIEL, Y. (ed.). Perspectives on historical linguistics. Amsterdam; Philadelphia: John Benjamins, 1982. p. 17-92.

. Padrões Sociolinguísticos. São Paulo: Parábola, 2008[1972]. 391 p.

LASS, R. On explaining language change. Cambridge: Cambridge University Press, 1980. $204 \mathrm{p}$.

LIGHTFOOT, D. Principles of diachronic syntax. Cambridge: Cambridge University Press, 1979. $421 \mathrm{p}$.

LUCCHESI, D. Sistema, mudança e linguagem: um percurso na história da linguística moderna. 2. ed. São Paulo: Parábola, 2004. 232 p.

Aspectos gramaticais do português brasileiro afetados pelo contato entre línguas: uma visão de conjunto. In: RONCARATI, C.; ABRAÇADO, J. (org.). Português brasileiro II: contato linguístico, heterogeneidade e história. Niterói: EDUFF, 2008. p. 366-390.

Os limites da variação e da invariância na estrutura da gramática. Revista da $\overline{A B R A L I N}$, v. elet., n. esp., p. 227-259. $2^{\mathrm{a}}$ parte, 2011.

LUCCHESI, D.; BAXTER, A.; SILVA, J. A. A transmissão Linguística Irregular. In: LUCCHESI; D.; BAXTER, A.; RIBEIRO, I. (orgs.). O Português Afro-Brasileiro. Salvador: Edufba, 2009. p. 101-124.

MARTINET, A. Économie des Changements Phonétiques. Berna: Francke, 1955. 395 p.

MCWHORTER, J. The world's simplest grammars are creole grammars. Linguistic Typology, 5 (2/3), p. 125-166, 2001. 
MUYSKEN, P.; VEENSTRA, T. Universalist approaches. In: ARENDS, J.; MUYSKEN, P.: SMITH, N. (eds.). Pidgins and creoles: an introduction. Amsterdam / Philadelphia: John Benjamis, 1994. p. 121-136.

MÜHLHÄUSLER, P. Pidgin \& Creole linguistics. Londres: Basil Blackwell, 1986. 320 p.

RAMPTON, B. A sociolinguistic perspective on L2 communication strategies. In: KASPER, G.; KELLERMAN, E. (eds.). Communication Strategies: Psycholinguistic and Sociolinguistic Perspectives. Londres/Nova York: Longman, 1997. p. 279-303.

RICKFORD, J. Dimensions of a creole continuum: history, texts and linguistic analysis of Guyanese Creole. Stanford: Stanford University Press, 1987. 351 p.

SAPIR, E. A linguagem: introdução ao estudo da fala. Tradução de J. Mattoso Câmara Jr. Rio de Janeiro: Instituto Nacional do Livro, 1954[1921]. 229 p.

SAUSSURE, F. Curso de Lingüística Geral. 5. ed. Tradução de Antônio Chelini, José Paulo Paes e Izidoro Blikstein. Prefácio de Isaac Nicolau Salum. São Paulo: Cultrix, 1973. $279 \mathrm{p}$.

SEUREN, P.; WEKKER, H. Semantic transparency as a factor in creole genesis. In: MUYSKEN, P.; SMITH, N. (eds.). Substrata versus universals in creole genesis. Amesterdam: John Benjamins, 1986. p. 57-70.

SIEGEL, J. The Emergence of Pidgin and Creole Languages. Oxford: Oxford Univers ity Press, 2008. 320 p.

TRUDGILL, P. Sociolinguistic typology and complexification. In: GEOFFREY, S.; GIL, D.; TRUDGILL, P. (eds.). Language Complexity as an Evolving Variable. Oxford: Oxford University Press, 2009. p. 98-109.

VAINIKKA, A.; YOUNG-SCHOLTEN, M. The roots of syntax and how they grow; Organic Grammar, the Basic Variety and Processability Theory. In: UNSWORTH, S. et alii (eds.). Paths of Development in L1 and L2 acquisition. Amsterdam; Philadelphia: John Benjamis, 2006. p. 77-106.

WEINREICH, U.; LABOV, W.; HERZOG, M. Fundamentos empíricos para uma teoria da mudança lingüística. São Paulo: Parábola, 2006[1968]. 152 p.

Recebido em: 10/04/2016

Aprovado em: 13/04/2016 